\title{
Using Econometric Models to Estimate the Relationship between Nanotechnology and the Added Value of Manufacturing
}

\author{
Abeer Mohamed Abdel Razek Youssef \\ Department of Applied Statistics and Econometrics Institute of Statistical \\ Studies and Research
}

\begin{abstract}
This study aims to use the panel models to estimate the impact of nanotechnology on economic growth represented in this study by the added value of manufacturing, by clarifying between the three models represented by the pooled regression model, the fixed effects model, and the random effects model. The Haussmann criterion was based on choosing the best model by studying two independent variables that affect technology. The study included two economic sectors, namely, the manufacturing sector and the scientific research sector related to nanotechnology, for the period from 2000 to 2022. The study concluded that the fixed effects model is better than the pooled regression model and the random effects in estimating the relationship between research variables related to nanotechnology and industrial development. The study concluded that there is a strong positive statistically significant relationship between nanotechnology and the added value of manufacturing.
\end{abstract}

Keywords: pooled regression model, fixed effects model, random effects model, value added, nanotechnology, industry, African countries. 


\section{Introduction}

\section{First: The concept of Panel data and its importance}

Panel data means the cross-sectional views (countries or companies) observed during a certain period of time

${ }^{1}$ This means that this data has two dimensions, the first: for the time series, and the second:

2 for cross sections. With regard to the time series, it describes the behavior of a single individual during a certain period of time. Whereas the cross-sectional data describe the behavior of a number of items at one time period, and the longitudinal data are either balanced or unbalanced. ${ }^{3}$

If all observations are equal for the study sample, the longitudinal data are balanced (Balanced Panel data); While it is unbalanced (Unbalanced Panel data) if there are missing observations for some of the study sample, and it should be noted that panel data has a synonymous term, it may also be called Longitudinal data. ${ }^{4}$ Longitudinal data models have gained increasing interest, particularly in economic studies; It takes into account the effect of the difference between the cross-sections and the effect of the change of time. ${ }^{5}$ 


\section{The methods for estimating the panel models are the following graph}

Figure1 Steps for estimating panel data models

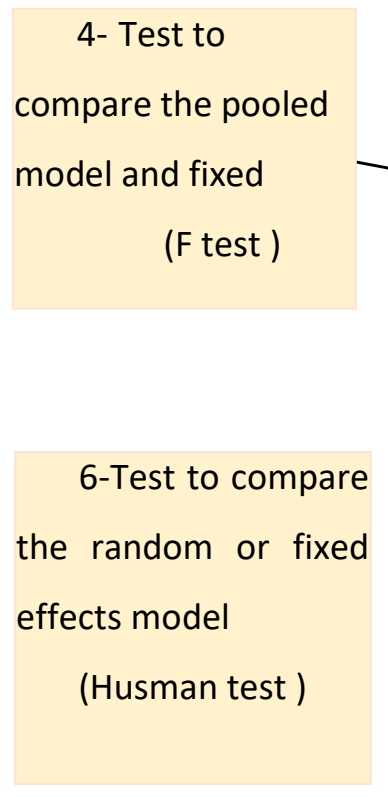

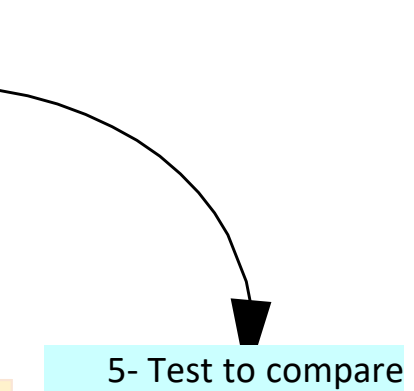

the pooled model and the random or fixed effects model (LM test )

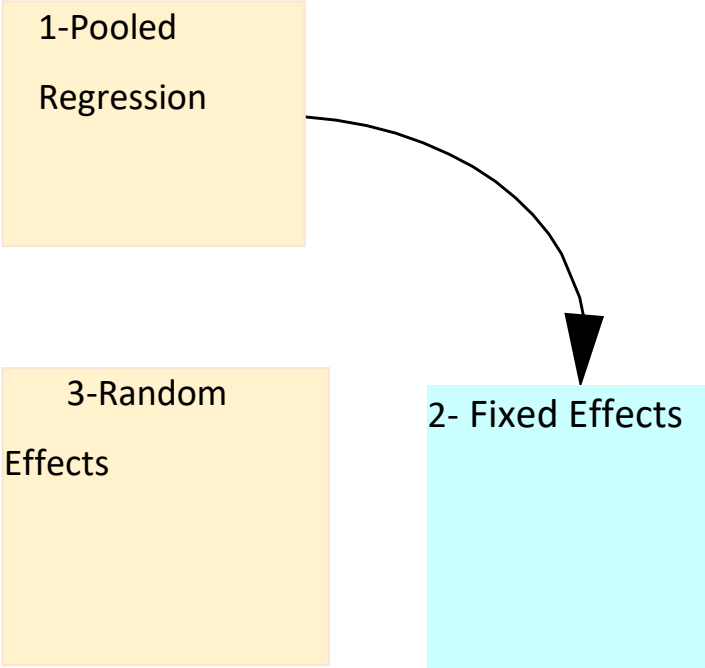

Gujarati, D. N. (2011). Econometrics by example.

\section{Practical framework for longitudinal data model}

First hypothesis: There is a positive significant relationship with statistical significance between the added value of manufacturing and nanotechnology.

Study variables: The variables used in estimating the model can be defined as follows:

Table 1 Study variables

\begin{tabular}{cccc}
\hline variable name & Definition & measruing unit & Variable type \\
\hline Add value & $\begin{array}{c}\text { Manufacturing, } \\
\text { value added }\end{array}$ & (current US\$) & dependent variable \\
\hline Nanotechnology & $\begin{array}{c}\text { Nanotechnology } \\
\text { publications (Article) }\end{array}$ & Numerical numbers & $\begin{array}{c}\text { independent } \\
\text { variable }\end{array}$ \\
\hline High-tech & $\begin{array}{c}\text { Medium and high- } \\
\text { tech Industry }\end{array}$ & $\begin{array}{c}\text { (\% manufacturing } \\
\text { value added) }\end{array}$ & $\begin{array}{c}\text { independent } \\
\text { variable }\end{array}$ \\
\hline
\end{tabular}

Source: Prepared by the researcher from www. statnano.com 


\section{Study population and sample:}

Value added was chosen as an indicator of industrialization for the sample of foreign countries and as a response variable (dependent); While The proportion of medium and high-tech industry and Number of nanotechnology-related articles indexed in Web of Science (WoS) were included as an independent and explanatory variable, the study covers foreign countries with available data representing 72 countries during the period 2000 to 2022, thus the number of observations used in the total sample is 1563 .

Table 2 the study countries

\begin{tabular}{|c|c|c|}
\hline Country & Country & Country \\
\hline 1- China & 27- Czech Republic & 49- Kazakhstan \\
\hline 2- USA & 28- Thailand & 50- Belarus \\
\hline 3- India & 29- Belgium & 51- Kuwait \\
\hline 4- Iran & 30- Portugal & 52- Croatia \\
\hline 5- South Korea & 31- Austria & 53- Lithuania \\
\hline 6- Germany & 32- Finland & 54- Estonia \\
\hline 7- Japan & 33- Denmark & 55- Lebanon \\
\hline 8- Saudi Arabia & 34- Romania & 56- Luxembourg \\
\hline 9- UK & 35- Ukraine & 57- Peru \\
\hline 10- France & 36- Greece & 58- Latvia \\
\hline 11- Russia & 37- Ireland & 59- Sri lanka \\
\hline 12- Spain & 38- Argentina & 60- Azerbaijan \\
\hline 13- Australia & 39- Norway & 61- Cyprus \\
\hline 14- Italy & 40- Chile & 62- Uruguay \\
\hline 15- Canada & 41- Hungary & 63- Bahrain \\
\hline 16- Pakistan & 42- Nigeria & 64- Moldova \\
\hline 17- Turkey & 43- Bangladesh & 65- Cuba \\
\hline
\end{tabular}


18- Brazil

19- Poland

20- Malaysia

21- Singapore

22- Sweden

23- Netherlands

24- Switzerland

25- Vietnam

26- Mexico
44- Slovakia

45- Slovenia

46- New Zealand

47- Serbia

48- Jordan
72- Costa rica

66- Georgia

67- Nepal

68- Uzbekistan

69- Iceland

70- North Korea

71- Venezuela

Source: Prepared by the researcher from www. statnano.com and www.worldbank.data

\section{Description of model variables}

Through this econometric model, we try to find out whether there is a relationship between the study variables and nanotechnology, by using panel models to reach the nature of this relationship (moral or insignificant), The estimation of the model depends on entering the variables in logarithmic form, using the EViews program.

\section{d- Estimating the model and verifying the hypothesis of the search}

Estimating the relationship between the added value of industrial development and scientific production of nanotechnology, By estimating the following function:

\section{LADD_VALUE $=\mathbf{f}($ LNANOTECHNOLOGY, LHIGH_TECH $)$}

First, estimate the cumulative regression model, fixed effects, and random effects 
In order to make the vision clear that to measure the impact of the scientific production of nanotechnology on industrial development, the longitudinal data model was used by applying three models, the aggregate regression model, the fixed effects model and the random effects model, and the results of these three models were reached as shown in the following table:

Table 3 Estimation of the pooled regression model and fixed and random effect

\begin{tabular}{|c|c|c|c|c|c|c|c|c|c|c|c|c|}
\hline \multicolumn{13}{|c|}{$\begin{array}{l}\text { Dependent Variable: LADD_VALUE } \\
\text { Sample: } 2000 \text { - } 2022 \\
\text { Cross-sections included: } 72 \\
\text { Total panel (balanced) observations: } 1563\end{array}$} \\
\hline \multirow[b]{2}{*}{ Variable } & \multicolumn{4}{|c|}{ Pooled Regression Model } & \multicolumn{4}{|c|}{ Fixed Effects Model } & \multicolumn{4}{|c|}{ Random Effects Model } \\
\hline & 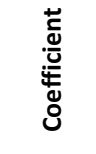 & $\begin{array}{l}\text { ᄒ̀ } \\
\text { ஸे } \\
\dot{D} \\
\dot{\omega}\end{array}$ & 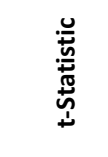 & 운 & 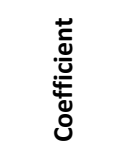 & 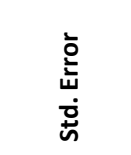 & 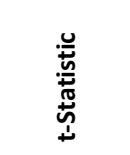 & 은 & 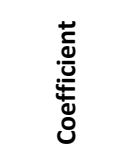 & 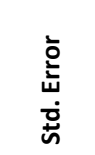 & 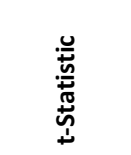 & 음 \\
\hline C & 17.907 & 0.1645 & 108.807 & 0.0000 & 22.18767 & 0.118806 & 186.7549 & 0.0000 & 22.02747 & 0.1592 & 138.326 & 0.0000 \\
\hline $\begin{array}{l}\text { LNANOTE } \\
\text { CHNOLOG } \\
Y\end{array}$ & 0.5145 & 0.0144 & 35.6475 & 0.0000 & 0.274375 & 0.006727 & 40.78767 & 0.0000 & 0.279149 & 0.0066 & 41.70706 & 0.0000 \\
\hline $\begin{array}{l}\text { LHIGH_TE } \\
\text { CH }\end{array}$ & 0.9717 & 0.0580 & 16.7317 & 0.0000 & 0.097909 & 0.035642 & 2.747007 & 0.0061 & 0.138922 & 0.0352 & 3.943864 & 0.0001 \\
\hline R-square & \multicolumn{4}{|c|}{0.695488} & \multicolumn{4}{|c|}{0.977658} & \multicolumn{4}{|c|}{0.540060} \\
\hline $\begin{array}{l}\text { Adjusted } \\
\text { R-squared }\end{array}$ & \multicolumn{4}{|c|}{0.695098} & \multicolumn{4}{|c|}{0.976562} & \multicolumn{4}{|c|}{0.539471} \\
\hline F-statistic & \multicolumn{4}{|c|}{1781.479} & \multicolumn{4}{|c|}{892.5523} & \multicolumn{4}{|c|}{915.8741} \\
\hline $\begin{array}{l}\begin{array}{l}\text { Prob(F- } \\
\text { statistic) }\end{array} \\
\end{array}$ & \multicolumn{4}{|c|}{0.000000} & \multicolumn{4}{|c|}{0.000000} & \multicolumn{4}{|c|}{0.000000} \\
\hline AIC & \multicolumn{4}{|c|}{2.876022} & \multicolumn{4}{|c|}{0.354639} & & & & \\
\hline BIC & \multicolumn{4}{|c|}{2.886299} & \multicolumn{4}{|c|}{0.608140} & & & & \\
\hline HQC & \multicolumn{4}{|c|}{2.879842} & \multicolumn{4}{|c|}{0.448883} & & & & \\
\hline
\end{tabular}

Source: Prepared by the researcher based on the statistical program EViews, 10th edition. (See the appendices, tables No. $\mathbf{7 , 8 , 9}$ ) 
The above table shows the results of testing the three panel models (Pooled, fixed and random), which were reached based on the available data that show the countries of the research sample. After the model has been estimated, a comparison is now made between these methods in order to rely on the best method. In order to reach this goal, the F-test is used to compare between the pooled regression model and between the fixed effects model and the random effects model. In order to choose the appropriate model to be used, the table (4) shows the F-test.

Secondly, the $F$ test and the Haussmann test for differentiation between the three models

The first method: Choosing between a cumulative regression model and a fixed effects model When choosing between a pooled regression model (PM) and a fixed effects model (FEM), the constrained F-test is used as follows:

$$
F(n-1, n T-n-K)=\frac{\left(R_{F E M}^{2}-R_{P M}^{2}\right) /(n-1)}{\left(1-R_{F E M}^{2}\right) /(n T-n-K)}
$$

Since:

$\mathrm{K}$ : the number of estimated parameters.

$\mathrm{R}_{\mathrm{FEM}}$ : coefficient of determination when using a fixed effects model (FEM) .

$\mathrm{R}_{\mathrm{PM}}$ : coefficient of determination when using a pooled regression model (PM).

After obtaining the calculated $\mathrm{F}$ value, it is compared with its tabular counterpart $((\mathrm{F}(\alpha, \mathrm{N}-1, \mathrm{Nt}-\mathrm{N}-\mathrm{k})$, if it is greater than it, or the value of the cross-section Chi-square is significant, the null hypothesis (H0) is rejected, And accept the alternative hypothesis (H1), that is, the fixed or random effects model is suitable for the study, but if the calculated $\mathrm{F}$ value is less than the tabular value, or the cross-section chi-square value is not significant, then the null hypothesis ( $\mathrm{H} 0)$ is accepted, and the hypothesis is rejected Alternative (H1), meaning that the pooled regression model (PM) is suitable for the study. 


\section{Table 4 F. test \\ Test Summary \\ Prob \\ Cross-section F \\ $\mathbf{0 . 0 0}$ \\ Source: Prepared by the researcher based on the statistical program EViews, 10th edition.}

The results of the F-test as shown in Table (26) showed that the probability of the F-test was significant at a level less than (0.01); Therefore, we reject the null hypothesis ( $\mathrm{HO})$, and accept the alternative hypothesis (H1), that is, the fixed or random effects model is the appropriate model for estimating the impact of nanotechnology on industrial development, and accordingly we move to the Hausman Test.

\section{Second, the Hausman test for choosing between a fixed-effects model and a random-effects model}

To make sure the most appropriate model is consistent with the data used in this study after the fixed effects and random effects model have been tested, the final judgment will be made based on the Hausman test

\section{Hausman test hypotheses:}

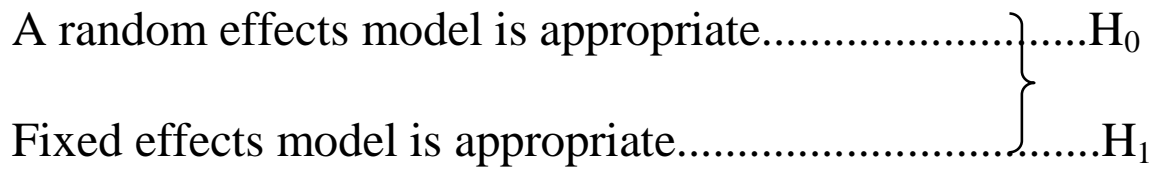


INTERNATIONAL JOURNAL OF

MULTIDISCIPLINARY STUDIES ON MANAGEMENT, BUSINESS, AND ECONOMY

The test results are shown in the following table:

\section{Table 5 Hausman Test}

\begin{tabular}{|c|c|c|c|}
\hline \multicolumn{2}{|c|}{ Correlated Random Effects- Hausman Test } & & \\
\hline \multicolumn{2}{|c|}{ Test cross-section Random Effects } & & \\
\hline Test Summary & Chi-Stat & Chi-sq. df & Prob \\
\hline Cross-section & 81.244657 & 2 & 0.0000 \\
\hline
\end{tabular}

Source: Prepared by the researcher based on the statistical program EViews 10th Edition. (See Appendices Table No. 17)

Table 6 fixed test

\begin{tabular}{|c|c|c|c|c|}
\hline \multicolumn{4}{|c|}{ Dependent Variable: LADD_VALUE } & \\
\hline \multicolumn{3}{|c|}{ Method: Panel Least Squares } & & \\
\hline \multicolumn{3}{|c|}{ Date: 10/24/21 Time: 10:01 } & & \\
\hline \multicolumn{3}{|l|}{ Sample: 20002022} & & \\
\hline \multicolumn{3}{|l|}{ Periods included: 23} & & \\
\hline \multicolumn{3}{|c|}{ Cross-sections included: 72} & & \\
\hline \multicolumn{4}{|c|}{ Total panel (unbalanced) observations: 1563} & \\
\hline Variable & Coefficient & Std. Error & t-Statistic & Prob. \\
\hline C & 22.18767 & 0.118806 & 186.7549 & 0.0000 \\
\hline $\begin{array}{c}\text { LNANOTECHNOLOG } \\
Y\end{array}$ & 0.274375 & 0.006727 & 40.78767 & 0.0000 \\
\hline \multirow[t]{2}{*}{ LHIGH_TECH } & 0.097909 & 0.035642 & 2.747007 & 0.0061 \\
\hline & \multicolumn{2}{|c|}{ Effects Specification } & & \\
\hline \multicolumn{4}{|c|}{ Cross-section fixed (dummy variables) } & \\
\hline R-squared & 0.977658 & \multicolumn{2}{|c|}{ Mean dependent var } & 24.01758 \\
\hline Adjusted R-squared & 0.976562 & \multicolumn{2}{|c|}{ S.D. dependent var } & 1.844109 \\
\hline S.E. of regression & 0.282320 & \multicolumn{2}{|c|}{ Akaike info criterion } & 0.354639 \\
\hline Sum squared resid & 118.6804 & \multicolumn{2}{|c|}{ Schwarz criterion } & 0.608140 \\
\hline Log likelihood & -203.1502 & \multicolumn{2}{|c|}{ Hannan-Quinn criter. } & 0.448883 \\
\hline F-statistic & 892.5523 & \multicolumn{2}{|c|}{ Durbin-Watson stat } & 0.375851 \\
\hline Prob(F-statistic) & 0.000000 & & & \\
\hline
\end{tabular}

Source: Prepared by the researcher based on the statistical program EViews 10th Edition 


\section{Substituted Coefficients:}

$\begin{array}{lll}\text { LADD_VALUE } & = & 22.1876727936 \\ 0.274374917648 * \text { LNANOTECHNOLOGY } & +\end{array}$
$0.0979094342961 *$ LHIGH_TECH $+[\mathrm{CX}=\mathrm{F}]$

1. Significance of parameters: The model coefficients with statistical significance are represented in the scientific production of nanotechnology and Medium and high-tech industry, where we find the probability of the fixed coefficient for each of them (0.0000), $(0.0061)$, respectively, because they are less than the level of significance (0.05). ) .

2. Overall Significance: Through the model, we find that the value of the F-statistic (0.000) is less than (0.05) indicating the overall Significance of the model, which is significant at the level of significance of $5 \%$, meaning that the model is totally significant.

3. Goodness of fit: The value of R2 is 0.977658 , meaning that the independent variables explain changes in industrial development by $97 \%$, and the rest is due to factors of variables outside the model, that is, explained by other variables that are not included in the model.

4. The positive sign of the scientific production coefficient for nanotechnology (0.274375) indicates the direct relationship between the added value and the scientific development in nanotechnology; When the production of nanoparticles increases by one unit, the add value increases by 0.274375 ; That is, increasing 
scientific research on nanotechnology increases economic growth rates.

5. Using econometric models and analyzing the relationship between value-added and nanotechnology, it was found that there is a significant positive impact of nanotechnology on industrial growth. This agrees with the hypothesis that there is a positive influence relationship between industrial growth and scientific outputs of nano-research, and therefore, through the results of estimating the fixed effects model, the model can be accepted from an economic point of view considering that the economic theory corresponds to the obtained results.

6. The integration of nanotechnology in manufacturing is one of the basic components of economic development to establish the bases of industrial production and to regulate the local and external competitive capabilities of the national economy, so that countries can achieve sustainable development that brings prosperity to its citizens, and enables it to occupy a distinguished competitive position among the countries of the world.

7. Industrialization requires relying on the data of science and knowledge in industrial production, which drives the development of income and the application of modern technological methods, and raising the ability to absorb the available resources. 

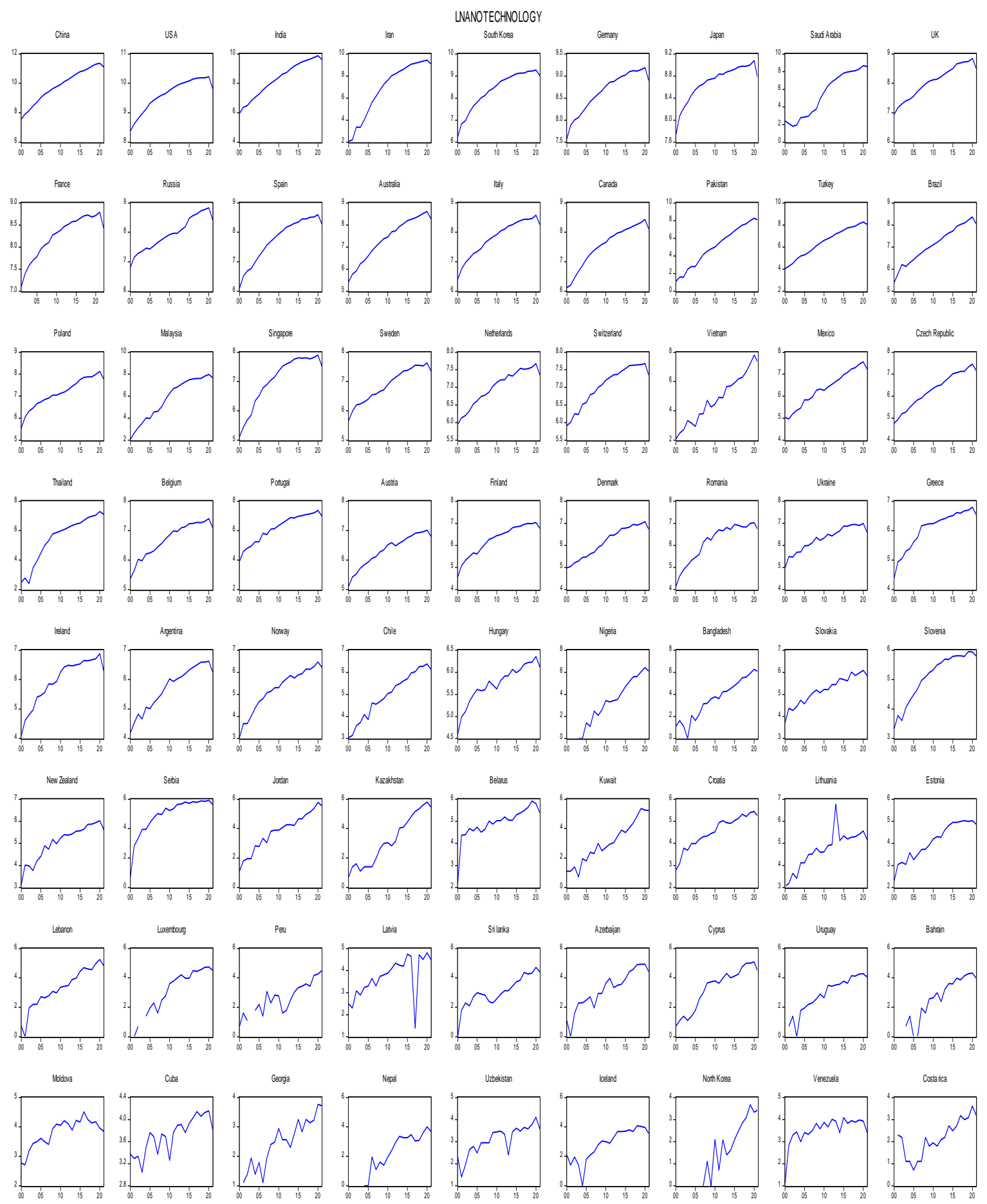

Source: Prepared by the researcher based on the statistical program EViews 10th Edition 

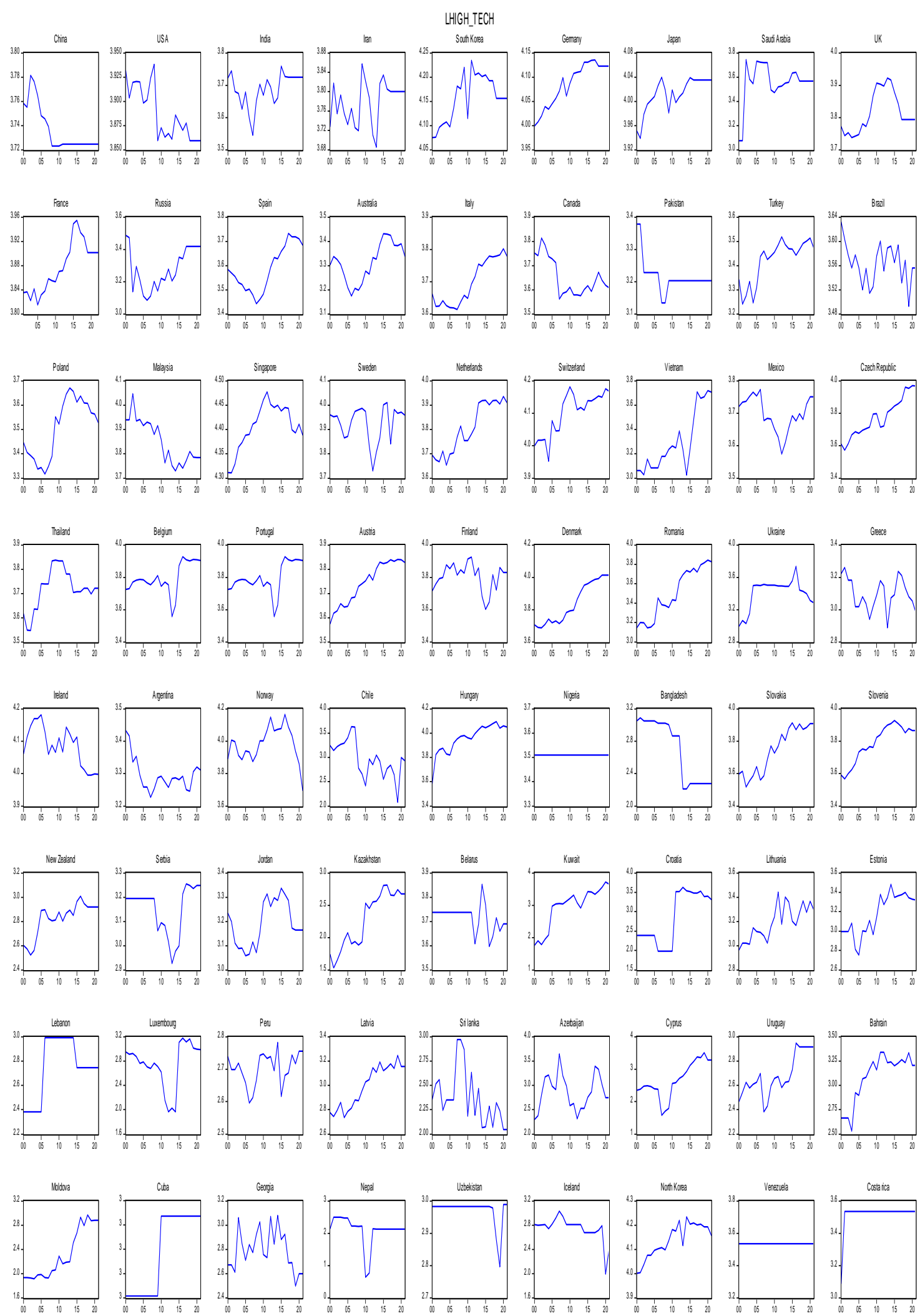

Figure 2 Trend of Medium and high-tech Industry development in African countries 

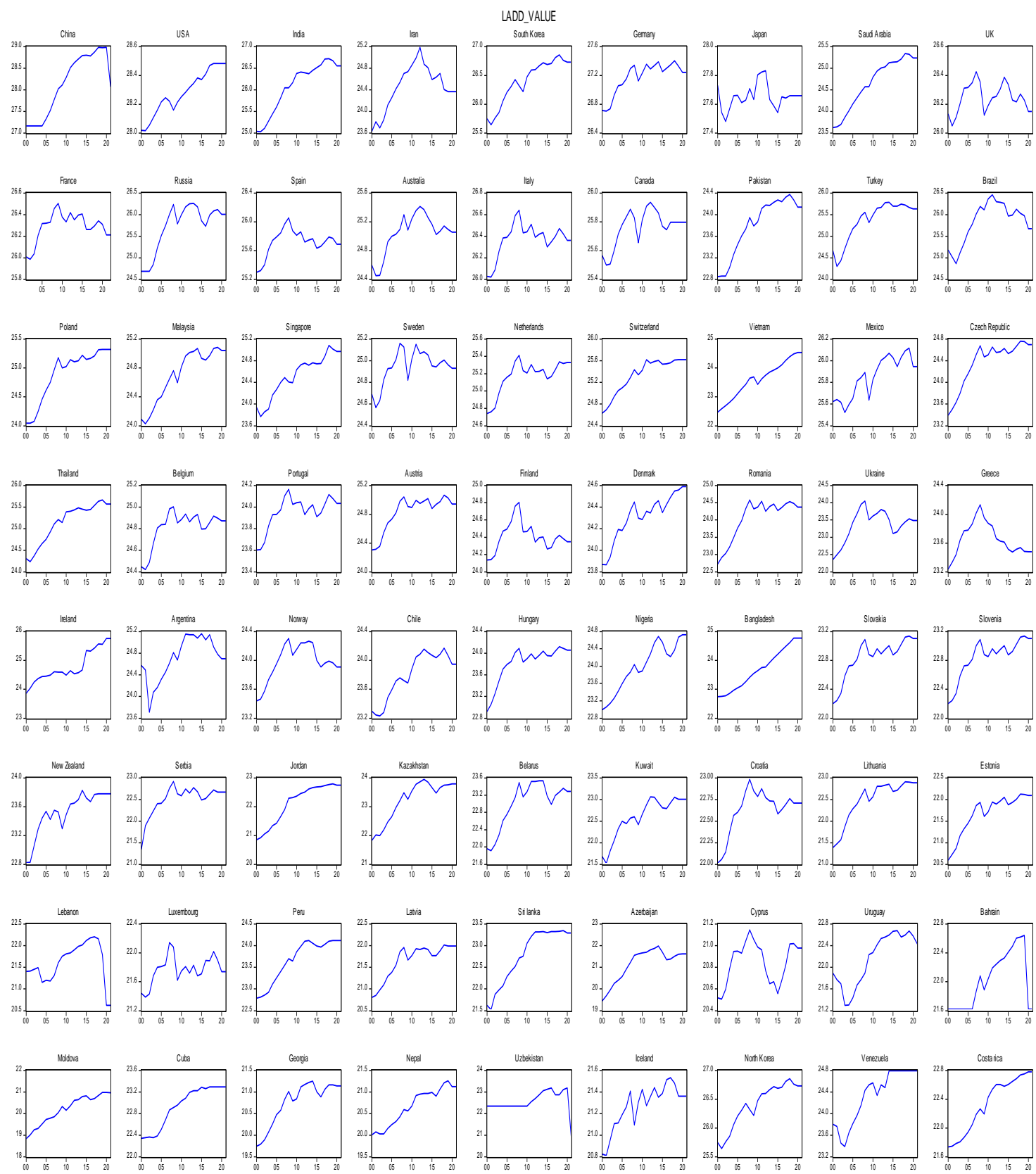

Source: Prepared by the researcher based on the statistical program EViews 10th

Edition

Figure 3 Trend of Medium and Add value Industry development in African countries

Source: Prepared by the researcher based on the statistical program EViews 10th

Edition 
The graphic shows that African countries have witnessed a boom in the nanotechnology industry, and it has increased at an accelerated pace by seizing opportunities to support environmentally friendly technological systems.

The share of the advanced technology category has increased in Africa, and the participation in global production of global value chains and integration in supply chains has increased. It has also increased in the share of added value resulting from intermediate exports and the stimulation of other sectors through forward and backward links.

Reaching advanced levels of comprehensive and sustainable industrial development requires moving towards a structural transformation of modern technologies such as nanotechnology and establishing resilient infrastructure, and then achieving sustainable growth in the long term.

\section{Conclusion:}

The study provided an assessment of the econometric models to measure the impact of nanotechnology's contribution to raising economic growth rates, by examining the relationship between scientific research of nanotechnology and the added value of manufacturing in various countries, and making a contribution to explore the methods available to verify the relationship between them using panel analysis, then working on the development of a proposed model to integrate nanotechnology receiving the art of modern technologies and adapt them to serve economic development, leading to the development of scientific infrastructure as one of the pillars of economic growth. 


\section{Reference}

${ }^{1}$ Andreß, H. J., Golsch, K., \& Schmidt, A. W. (2013). Applied panel data analysis for economic and social surveys. Springer Science \& Business Media.

2 Yaffee, R. (2003). A primer for panel data analysis. Connect: Information Technology at NYU, 1-11.

${ }^{3}$ Hsiao, C. (2007). Panel data analysis - advantages and challenges. Test, $16(1), 1-22$.

4 Frees, E. W. (2004). Longitudinal and panel data: analysis and applications in the social sciences. Cambridge University Press.

${ }^{5}$ Raj, B., \& Baltagi, B. H. (Eds.). (2012). Panel data analysis. Springer Science \& Business Media. 